固 

Mohammed Rashed .

Das Opferfest im heutigen Ägypten 


\author{
begründet \\ von \\ Klaus Schwarz \\ herausgegeben \\ von \\ Gerd Winkelhane
}




\title{
Mohammed Rashed
}

\author{
Das Opferfest ( ${ }^{c} \bar{T} d$ al-aḍhāā) \\ im heutigen Ägypten
}


Die Deutsche Bibliothek - CIP-Einheitsaufnahme

\section{Rashed, Mohammed:}

Das Opferfest ('Td al-aḍhā) im heutigen Ägypten/Mohammed Rashed. Berlin : Schwarz, 1998

(Islamkundliche Untersuchungen ; Bd. 215)

Zugl.: Mainz, Univ., Diss., 1996

ISBN 3-87997-267-2

Alle Rechte vorbehalten.

Ohne ausdrückliche Genehmigung des Vertages

ist es nicht gestattet, das Werk oder einzelne Teile daraus

nachzudrucken oder zu vervielfältigen.

(c) Gerd Winkelhane, Berlin 1998.

Klaus Schwarz Verlag GmbH, Postfach 4102 40, D-12112 Berlin

ISBN 3-87997-267-2

Druck: Oftsetdruckerei Gerhard Weinert GmbH, D-12099 Bertin

ISSN 0939-1940

ISBN 3-87997-267-2 


\author{
Diese Arbeit widme ich \\ meiner Tochter Nura, \\ die am ersten Tag des Opferfestes 1992 \\ zur Welt kam
}


